\title{
Postoperative lumbar spinal stenosis after intertransverse fusion with granules of hydroxyapatite: a case report
}

\author{
Gen Inoue ${ }^{1 *}$, Seiji Ohtori ${ }^{2}$, Tomoyuki Ozawa ${ }^{3}$, Toshinori Ito $^{2}$, Morihiro Higashi ${ }^{4}$, Kazuyo Yamauchi ${ }^{2}$, Sumihisa Orita ${ }^{2}$, \\ Junichi Nakamura ${ }^{2}$, Tomoaki Toyone ${ }^{3}$, Masashi Takaso ${ }^{1}$ and Kazuhisa Takahashi ${ }^{2}$
}

\begin{abstract}
In the present case of postoperative lumbar spinal stenosis after non-instrumented intertransverse fusion with granules of hydroxyapatite (HA), bone union was not completed and the patient felt the recurrence of his symptoms within two years. We performed re-decompression with fusion, and in hematoxylin and eosin staining of HA granulation harvested during revision surgery, fibrous tissue with hyaline degeneration surrounded the cavity where the HA had existed. Multinuclear giant cells and lymphocytes infiltrated some parts of the marginal layer of the cavity, and no obvious bony bridge had regenerated from autologous bone. No tartrate-resistant acid phosphate (TRAP) -positive osteoclasts could be seen in the new bone, suggesting that the activity of osteoclasts in the new bone decreased during the seven years after the primary surgery.
\end{abstract}

Virtual slides: The virtual slide(s) for this article can be found here: http://www.diagnosticpathology.diagnomx.eu/ vs/3483360258050263

Keywords: Nonunion, Lumbar spine, Intertransverse fusion, Hydroxyapatite

\section{Case report}

A 76-year-old man with lumbar spinal stenosis was admitted to our hospital with low back pain and bilateral sciatica. For his low back and bilateral leg pain, he had undergone L4/L5 non-instrumented intertransverse fusion with granules of HA for lumbar spinal stenosis in another hospital seven years before. After surgery, his complaint disappeared completely, however, after two years, he once again felt low back pain and increasing bilateral sciatica. On admission, he showed intermittent claudication after 20 meters, and lateral roentgenograms showed instability, suggesting failure of the attempted posterolateral intertransverse fusion. Computed tomography showed that hardly any bone had formed around the HA and no bony intertransverse bridge existed between the transverse process and HA (black arrow heads; Figure 1A). Magnetic resonance imaging (MRI) of

\footnotetext{
* Correspondence: ginoue@kitasato-u.ac.jp

${ }^{1}$ Department of Orthopaedic Surgery, Kitasato University, School of Medicine, 1-15-1 Kitasato, Minami-ku, Sagamihara, Kanagawa 252-0374, Japan Full list of author information is available at the end of the article
}

the T2 wedged axial plane revealed a high intensity area between the mass of hydroxyapatite and the transverse process. Enhancement with gadolinium was observed around the transplanted HA, suggesting failure of the intertransverse fusion (Figure 1B). Decompression and instrumented intertransverse fusion with autologous iliac bone for L4/L5 were performed after removal of the HA granulation. Both sides of the granules of HA that formed an en bloc mass were resected obtusely and evaluated histologically.

\section{Histological findings}

In hematoxylin and eosin staining of the sagittal section of the resected mass, fibrous tissue with hyaline degeneration surrounded the cavity where the HA had existed. Multinuclear giant cells and lymphocytes infiltrated some parts of the marginal layer of the cavity, and partially formed foreign-body granulomas. New bone formation was observed in a limited area in the cavity where the HA had been, or just beside the fibrous tissue. Most of this new bone was necrotic. Bone marrow formation was not seen in any sections (Figure 2A-D). In tartrate-resistant acid 

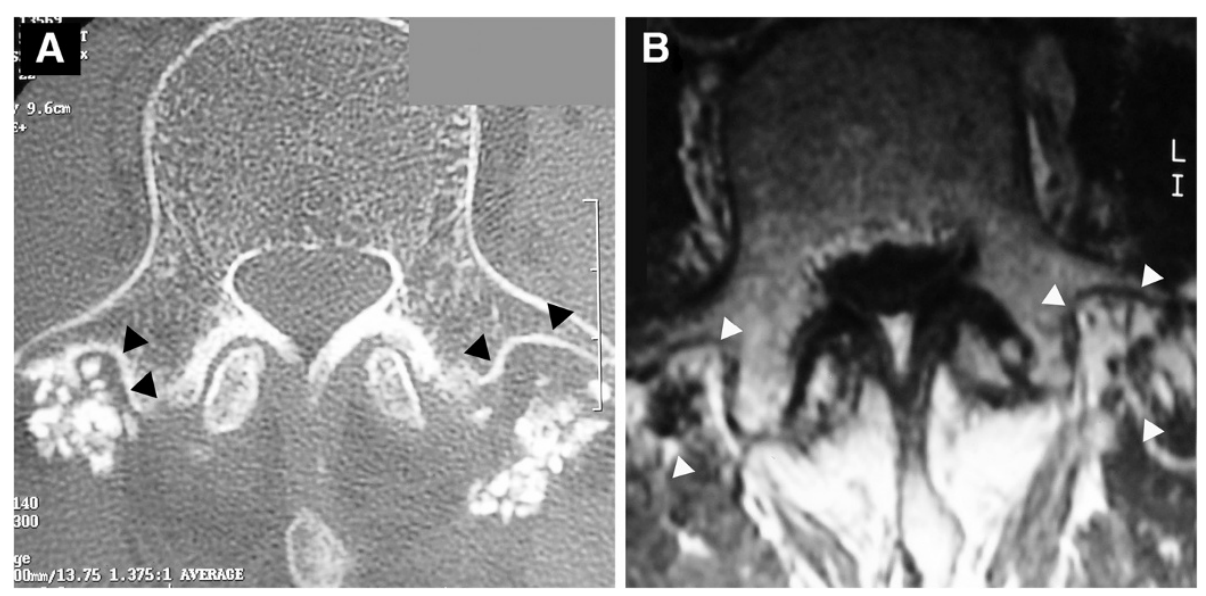

Figure 1 Preoperative imagings A; Computed tomography of L4 showing scant bone formation around the granulation tissue and few bony intertransverse bridges between the transverse process and HA. Because of intervening fibrous tissue, contact between HA and the vertebrae is limited (arrowheads). B; Gadolinium-enhanced magnetic resonance imaging (MRI) of L4. Enhancement was observed around transplanted HA (arrowheads), suggesting failure of the posterolateral fusion.

phosphate (TRAP) staining, TRAP-positive osteoclasts were not seen in the new bone in spite of the presence of TRAPpositive osteoclasts in the section of the spinous process that was harvested during the surgery (Figure 3). These findings suggest that the activity of osteoclasts decreased during the seven years after the primary surgery and that insufficient formation of new bone around the HA granules resulted in failure of the intertransverse fusion.

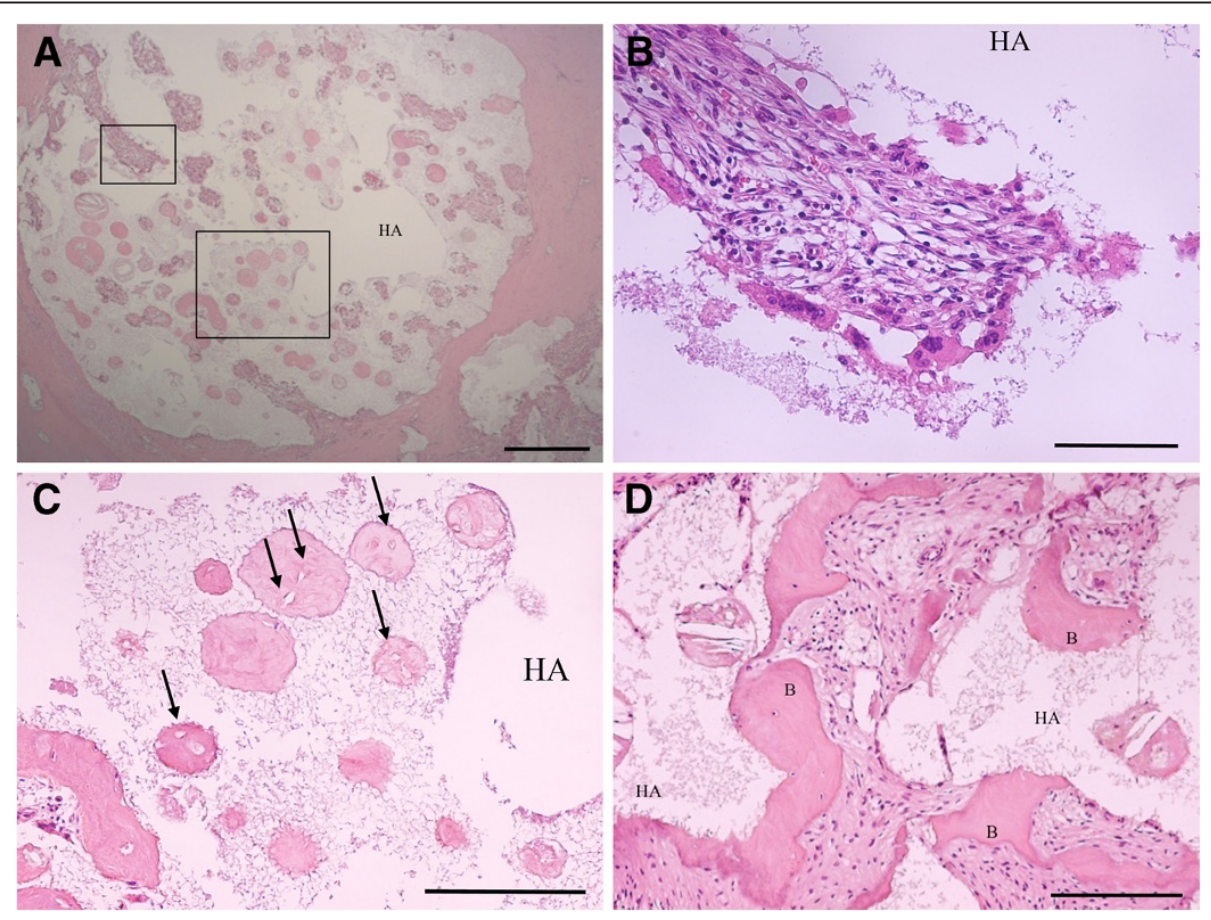

Figure 2 Hematoxylin and eosin staining of a sagittal section of the resected mass. A; Fibrous tissue with hyaline degeneration surrounded the cavity where HA existed. (magnification, $\times 25$; scale bar, $500 \mu \mathrm{m}$ ). B; A higher magnification of the boxed area in Figure A. In some parts of the marginal layer of the cavity, multinuclear giant cells and lymphocytes were observed, partially forming a foreign body granuloma (magnification, ×200; scale bar, $100 \mu \mathrm{m}$ ). C; A higher magnification of the boxed area in Figure A. Scant new bone formation is found in the HA cavity, or juxtaposed with fibrous tissue. Some new bone was necrotic. Black arrows indicate necrotic bone without osteocytes (magnification, $\times 100$; scale bar, $200 \mu \mathrm{m})$. D; Further observation of new bone formation juxtaposed with fibrous tissue. Osteocytes were present in the new bone, but bone marrow formation was not observed (magnification, ×100; scale bar, 200 m). 'B', New bone. 

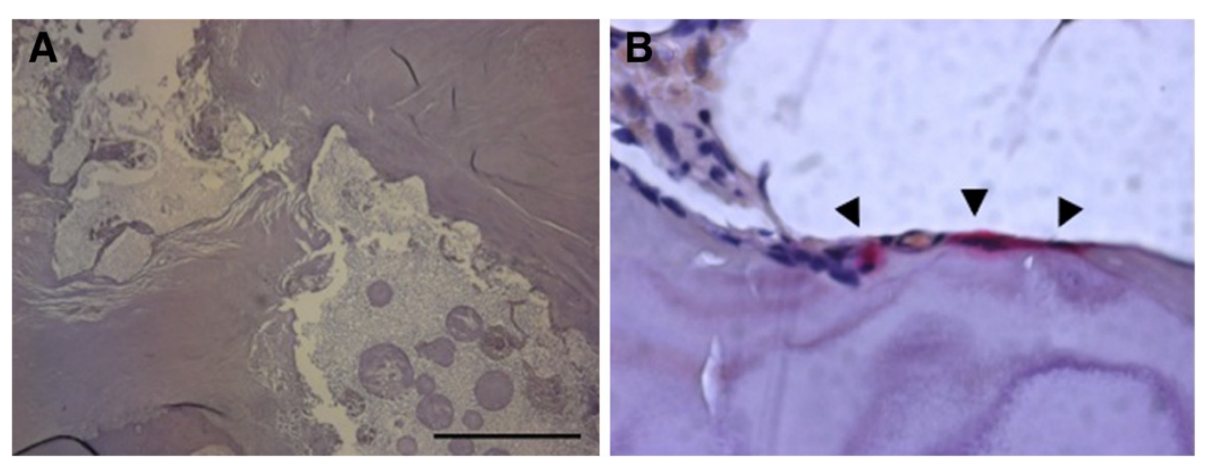

Figure 3 Tartrate-resistant acid phosphatase (TRAP) staining of a sagittal section of the resected mass. A; No TRAP-positive osteoclasts could be seen around the new bone or the cavity (scale bar, $500 \mu \mathrm{m}$ ). B; Bone tip harvested from a spinous process during the corrective surgery was used as a positive control. Some TRAP-positive osteoclasts were observed (arrow heads).

\section{Discussion}

Since the first report in 1953, lumbar posterolateral intertransverse fusion has been most commonly performed for patients with lumbar instability and has been reported to achieve successful union and clinical outcomes [1-5]. Recently, hydroxyapatite (HA) has been used as a substitute for autologous bone graft, and there have been no detailed reports of failure of intertransverse fusion with HA [6,7].

There have been few reports of long-term follow-up in cases of intertransverse fusion with granules of HA. It is reported that macrophages responding to HA particles are capable of osteoclast differentiation, and new bone formation occurs between and within HA granules when bone union is successful [8]. In the present case, histological findings showed that formation of osteoclasts did not continue and that activity of these cells ceased within seven years. This was accompanied by insufficient bone formation from failure of coupled remodeling. On the other hand, in some parts of the marginal layer of the cavity, multinuclear giant cells and lymphocytes were observed, partially forming a foreign body granuloma. These cells are usually observed with HA, but few inflammatory reaction was observed in the whole tissue which was resected, indicating patient's pain was not induced by inflammation of the transplanted tissue, but might be induced by another unstable structures including the intervertebral discs or facet joints [9-11]. Motomiya et al [12]. reported the bony bridge which is achieved within autologous bone graft may be formed more easily and earlier than bone ingrowth to HA, but no obvious bony bridge which regenerated from autologous bone was seen in the present case. The exact pathomechanism for nonunion is unclear, but for spinal fusion, factors in the host (e.g., nutrition, age, smoking, mechanical stress), in biology (type or quality of bone graft, fusion site preparation, internal fixation), or in postoperative care (activity level, external immobilization) are reported to affect the union success rate in both human and animal studies $[13,14]$. These complex factors might influence bone formation and may have induced failure of the intertransverse fusion.

Also, preparation of fusion site might be insufficient in this case. More careful preparation of the soft tissue bed or bone surface onto which the graft material is placed might be necessary, the importance of which is indicated in previous reports $[15,16]$.

Recently, many factors (e.g., growth factor, bone morphogenetic protein) that stimulate bone formation have been investigated as a substitute for autologous bone graft, but these kinds of bone substitutes are still prohibited for spine surgery in Japan $[17,18]$. So, most bone substitutes that are used in Japan are HA and $\beta$ tricalcium phosphate, which can provide a scaffold for new bone formation. Because fusion status is critical to achieve good post-operative results, research in failed cases is very important [19]. Further understanding of the causes and mechanisms of nonunion are important to achieve higher union rates and to avoid poor clinical results in patients after surgery.

\section{Consent}

Written informed consent was obtained from the patients for publication of this case report and any accompanying images.

\section{Competing interests}

The author(s) declared no conflicts of interest with respect to the authorship and/or publication of this article.

\section{Authors' contributions}

$\mathrm{Gl}$ and $\mathrm{MH}$ carried out the histochemical explorations. SO, TO, TI and KT participated in the surgery and the design of the study. JN, TT and MT conceived the study and have been involved in the literature search. Gl, KY and SO drafted the manuscript. All authors read and approved the final manuscript. 


\section{Funding}

The author(s) received no financial support for the research and/or authorship of this article.

\section{Author details}

'Department of Orthopaedic Surgery, Kitasato University, School of Medicine, 1-15-1 Kitasato, Minami-ku, Sagamihara, Kanagawa 252-0374, Japan. ${ }^{2}$ Department of Orthopaedic Surgery, Graduate School of Medicine, Chiba University, 1-8-1 Inohana, Chuo-ku, Chiba 260-8670, Japan. ${ }^{3}$ Department of Orthopaedic Surgery, Teikyo University Chiba Medical Center, 3426-3 Anesaki, Ichihara, Chiba 299-0111, Japan. ${ }^{4}$ Department of Pathology, Saitama Medical Center, Saitama Medical University, 1981 Kamoda, Kawagoe, Saitama 350-8550, Japan

Received: 13 September 2012 Accepted: 30 October 2012 Published: 7 November 2012

\section{References}

1. Bjarke Christensen F, Stender Hansen E, Laursen M, Thomsen K, Bunger CE: Long-term functional outcome of pedicle screw instrumentation as a support for posterolateral spinal fusion: randomized clinical study with a 5-year follow-up. Spine 2002, 27:1269-1277.

2. France JC, Yaszemski MJ, Lauerman WC, Cain JE, Glover JM, Lawson KJ, Coe JD, Topper SM: A randomized prospective study of posterolateral lumbar fusion. Outcomes with and without pedicle screw instrumentation. Spine 1999, 24:553-560

3. Korsgaard M, Christensen FB, Thomsen K, Hansen ES, Bunger C: The influence of lumbar lordosis on spinal fusion and functional outcome after posterolateral spinal fusion with and without pedicle screw instrumentation. J Spinal Disord Tech 2002, 15:187-192.

4. Thomsen K, Christensen FB, Eiskjaer SP, Hansen ES, Fruensgaard S, Bunger CE: Volvo Award winner in clinical studies. The effect of pedicle screw instrumentation on functional outcome and fusion rates in posterolateral lumbar spinal fusion: a prospective, randomized clinical study. Spine 1997, 22:2813-2822.

5. Watkins MB: Posterolateral fusion of the lumbar and lumbosacral spine. J Bone Joint Surg Am 1953, 35:1014-1018.

6. Gupta MC, Maitra S: Bone grafts and bone morphogenetic proteins in spine fusion. Cell Tissue Bank 2002, 3:255-267.

7. Spivak JM, Hasharoni A: Use of hydroxyapatite in spine surgery. Eur Spine J 2001, 10:S197-S204.

8. Sabokbar A, Pandey R, Diaz J, Quinn JM, Murray DW, Athanasou NA: Hydroxyapatite particles are capable of inducing osteoclast formation. J Mater Sci Mater Med 2001, 12:659-664.

9. Zenmyo M, Yamamoto T, Ishidou Y, Komiya S, ljiri K: Osteoid osteoma near the intervertebral foramen may induce radiculopathy through tumorous inflammation. Diagn Pathol 2011, 6:10.

10. Panelos J, Voulgaris S, Michos E, Doukas M, Charalabopoulos K, Batistatou A: Chondrosarcoma of the spine: a rare case with unusual presentation. Diagn Pathol 2006, 1:39.

11. Ghanaati S, Barbeck M, Detsch R, Deisinger U, Hilbig U, Rausch V, Sader R, Unger RE, Ziegler G, Kirkpatrick CJ: The chemical composition of synthetic bone substitutes influences tissue reactions in vivo: histological and histomorphometrical analysis of the cellular inflammatory response to hydroxyapatite, beta-tricalcium phosphate and biphasic calcium phosphate ceramics. Biomed Mater 2012, 7:015005.

12. Motomiya M, Ito M, Takahata M, Kadoya K, Irie K, Abumi K, Minami A: Effect of Hydroxyapatite porous characteristics on healing outcomes in rabbit posterolateral spinal fusion model. Eur Spine J 2007, 16:2215-2224.

13. Boden SD, Sumner DR: Biologic factors affecting spinal fusion and bone regeneration. Spine 1995, 20:102S-112S

14. Holmes R, Hagler $\mathrm{H}$ : Porous hydroxyapatite as a bone graft substitute in maxillary augmentation. An histometric study. J Craniomaxillofac Surg 1988, 16:199-205.

15. Allen BL Jr, Ferguson RL: The operative treatment of myelomeningocele spinal deformity-1979. Orthop Clin North Am 1979, 10:845-862.

16. Hurley LA, Stinchfield FE, Bassett AL, Lyon WH: The role of soft tissues in osteogenesis. An experimental study of canine spine fusions. J Bone Joint Surg Am 1959, 41:1243-1254.

17. Cowan CM, Soo C, Ting K, Wu B: Evolving concepts in bone tissue engineering. Curr Top Dev Biol 2005, 66:239-285.
18. Samartzis $D$, Khanna N, Shen FH, An HS: Update on bone morphogenetic proteins and their application in spine surgery. J Am Coll Surg 2005, 200:236-248.

19. Tsutsumimoto T, Shimogata M, Yoshimura Y, Misawa H: Union versus nonunion after posterolateral lumbar fusion: a comparison of long-term surgical outcomes in patients with degenerative lumbar spondylolisthesis. Eur Spine J 2008, 17:1107-1112.

doi:10.1186/1746-1596-7-153

Cite this article as: Inoue et al:: Postoperative lumbar spinal stenosis after intertransverse fusion with granules of hydroxyapatite: a case report. Diagnostic Pathology 2012 7:153.

\section{Submit your next manuscript to BioMed Central and take full advantage of:}

- Convenient online submission

- Thorough peer review

- No space constraints or color figure charges

- Immediate publication on acceptance

- Inclusion in PubMed, CAS, Scopus and Google Scholar

- Research which is freely available for redistribution
Biomed Central 